\title{
A Portrait of the Adult Learner: Pluralistic Interpretations of Literacy Learning Outcomes Over the Years
}

Maurice Taylor and David Trumpower, University of Ottawa

\begin{abstract}
In Canada, various studies investigating literacy learning have contributed to our understanding of the lives of the adult student. Through a consolidation of empirical evidence, a portrait of the adult learner is sketched, drawing upon pluralistic interpretations of the important life changes that have resulted from their participation in literacy education. This portrait highlights the significance of a variety of learning outcomes that go beyond traditional measures of knowledge and skills acquisition, with an emphasis on the relevance of such outcomes for different types of literacy learners, in various settings, and along three diverse learning pathways. International implications are highlighted in the discussion.
\end{abstract}

Keywords: adult literacy, learning outcomes, diverse learning pathways

There has been much debate about how to define and measure adult literacy education outcomes. In Canada, like many other Organisation for Economic Co-operation and Development (OECD) countries, the understanding of literacy and its definitions for program outcomes and policy development have shifted over time. An earlier sociocultural understanding of literacy learning through a humanistic and citizenship lens has moved to more of a human capital approach (Osmond, 2016; Taylor, Trumpower, et al., 2017). Within this economic lens, adult learners are streamed into formal skills training for employment or transition to post-secondary education. Belzer and Kim (2018) suggest that the focus of such programs is on measured outcomes that are expected to make participants more employable or upskilled to retain their jobs. As Tett (2018) explains, such training programs are designed around a narrow skills-focused pedagogy and outcomes. However, the scope of adult literacy learning outcomes is much broader than this.

The purpose of this article is to consolidate research findings over recent years on how adult literacy education has contributed to important life changes and outcomes for the adult learner. It draws from Canadian research funded through five major Social Sciences and Humanities Research Council (SSHRC) grants during an era when adult literacy as a field was maturing. Using the analogy of an adult learner "portrait," it 
highlights the importance of a variety of learning outcomes that go beyond traditional measures of knowledge and skills acquisition. Although built on Canadian evidence, the implications extend to other nations who have invested in the Programme for the International Assessment of Adult Competencies (PIAAC) such as the United States, Australia, New Zealand, United Kingdom and other Western countries. The canvas for this portrait will emphasize the relevance of such outcomes for different types of literacy learners, in various settings, along three diverse learning pathways. The journeys that are documented include: collaboration in communities of literacy learners and partnership building; adults acquiring higher skills during the life course; and mature adult learners experiencing identity transformation.

\section{Lifelong Learning as an Organizing Framework}

As a means of situating the three pathways, an organizing framework taken from the lifelong learning literature frames our adult learner portrait. Recently, the UNESCO Institute for Lifelong Learning (2009) has expanded the conceptualization of lifelong learning as all purposeful learning activity across the lifespan including "learning activities in all settings from formal education to informal and non-formal learning" (p. 472-473). Embedded in this concept are ideas related to lifelong, life-wide and lifedeep learning. Aspin et al. (2012) explain that throughout the life course there is interplay of informal, non-formal and formal learning that happens in different contexts and refer to this as life-wide. As well, they discuss the importance of recognizing the social, moral, ethical and religious dimensions of human experience and designate this as life-deep.
Knox et al. (2017) have suggested that outcomes in adult learning activities take various forms. These outcomes tend to be cumulative, with lifelong connections that are associated with the learning activities and often "have results beyond achieving program objectives” (p. 296). Examples of such outcomes range from discovery of new learning opportunities in everyday experiences to the development of social networks. However, as Smith (2017) claims, many formal adult basic education (ABE) programs and accompanying assessment protocols are driven by the guiding philosophy of the service provider, the funding agency, the theories about learning that are endorsed by the program directors and a standardized curriculum. Moreover, she maintains that such formal programs that have a singular focus on skills development may be short sighted and ineffective. Similarly, Hill (2017) reports that funding for formal adult literacy programs have imposed a marketoriented approach. This often means that goals of learners may become secondary to mastery of a standardized curriculum.

Werquin (2010) suggests that policies are increasingly focusing on outcomes and take a lifelong learning perspective which emphasizes a variety of learning contexts. Formal and informal learning could be considered as the two extremities of a learning continuum with nonformal learning situated somewhere between. Outcomes, on the other hand, have been defined as the knowledge, skills and competencies that people have acquired as a result of learning. Fittingly, Werquin (2010) adds that outcomes are much broader than knowledge and skills, but can be difficult to measure, codify and be recognized socially. To illuminate these broader adult literacy education outcomes, we now sketch the three pathways which are the essence of our emerging adult learner portrait. 


\section{The Three Pathways}

\section{Collaboration in Communities of Literacy Learners and Partnership Building}

In the first component of our composition, we see adult learners in communities of literacy practice, learning with and from each other. Too often, the measurable outcomes of adult literacy programs, such as the acquisition of literacy and numeracy skills, are conceived of as individual phenomenon. However, as Taylor et al. (2003) recognized, adult learners develop such skills through participation in collaborative practices. In a case study of four adult literacy classrooms in an Eastern Ontario Literacy and Basic Skills Program, these authors showed how collaborative learning activities, such as scaffolding and cognitive apprenticeships, help learners develop independence and social skills that have wide-ranging transferability to the workplace, home and community environments. They also revealed that collaborative learning can be supported by enabling, rather than directive, teaching styles as instructors identified their own beliefs about teaching. One implication of this study, and those described below, is that a restricted focus on immediate skill acquisition cannot account for the longer term, life-wide and life-deep impact of adult literacy programs.

Taylor, Abasi, et al. (2007) explored in greater depth how communities of literacy practice develop and lead to long-term outcomes during the life course. Investigating formal and nonformal adult literacy programs offered by two school boards, a community college career and access program, and a community tutorial literacy program, they found that some of the outcomes which result from engagement in communities of practice include attitudes and skills that are highly useful and valued in the workplace, community and home. In communities of literacy practice, learners move from being guided on their journey towards a pathway opening to independent learning, taking on increasing levels of responsibility. When they first embark on this path, learners may be reluctant to seek assistance from instructors or peers, due to lack of confidence, communication skills, or knowledge about who to ask for help. However, they observe and learn from more knowledgeable peers. As their confidence increases, they assume the role of more knowledgeable other and can share their understanding, model their newfound skills and coach others in their community of learning. Such collaborative practices provide opportunities for further developing communication abilities, self-esteem, and confidence. These are crucial growth outcomes as they try to better themselves as parents, spouses, workers, and citizens. As one instructor of a formal literacy program noted, "It gives the students the opportunity to explain or express their opinion; all those soft skills which the academic environment does not mark and does not necessarily evaluate. But in real work, in a community, they are valued highly. When you are teaching something to someone, you have to justify your choices, how to express yourself, and to convince others" (as cited in Taylor, Abasi, et al., 2007, p. 8).

Taylor, Evans, et al. (2007), in a mixed methods study of five adult literacy programs in Canada and three workplace basic skills programs in public sector organizations in the United Kingdom, were able to elucidate some specific collaborative skills that learners develop, which transfer to the workplace and everyday life. Among them is negotiation - a complex process involving an evaluation of one's own learning needs, perceptions of the abilities of peers, and decisions around who in a community of learners has common learning goals and common cultural and life experiences. 
Developing such a multidimensional skill also requires a recognition and appreciation of the benefits of social learning. In the workplace and the world outside the classroom, rarely does learning occur through direct transmission of knowledge. Moving beyond short-term skill acquisition, this learning outcome involves a more active and collaborative process of seeking information, making sense of it, and sharing it. It also encompasses metacognitive awareness of the competencies that one lacks, how and whom to ask for help in increasing them, developing communication skills and confidence, and building respectful relationships that support the giving and receiving of information. That is, it comprises a valuable skillset which facilitates sustained learning and illustrates the valuable outcomes of collaborative learning that occur in formal and non-formal adult literacy programs.

Another type of community of literacy practice was found in an Adult Learning Centre for indigenous adults in Northern Ontario (Hauer \& Taylor, 2008). In this qualitative case study, interactions among indigenous learners, instructors and the learning environment were investigated. Rather than recounting any shortterm program outcomes which were not a requirement of the funder, attention was given to the lifelong learning process of adults in the Centre. A metaphor of entering a house of literacy learning was developed to describe how learners become part of a community of literacy practice. Initially, an individual comes to the program with hopes and dreams for the future, including personal goals, further education, or employment preparation. For example, one participant stood at the threshold of the Literacy Centre with her dream to help her own children with their homework and decided to enter as the next phase of her life journey.
Once an individual decides to cross the threshold, he or she steps forward into the house of literacy learning and engagement in activities begins. These include developing a sense of personal safety, encouraging a sense of respect for the learners, increasing motivation, and forming groups of like-minded learners. In addition, the physical environment of the Centre had much to do with developing the community of literacy practice. Once learners enter the house of literacy learning they notice a large round table located in the middle of the room signifying the importance of building relationships. As the Director of the Centre stated, "Aboriginal adults learn through relationships and communication with others rather than through engaging with printed information." It was this interchange among learners and instructors that was key to the development of a community of literacy practice. Depending on the learning situation, individuals changed their role, moving from newcomer to mature group member and back. For example, in a Japanese language class, the mature group members tended to be individuals who had previously learned a second or third language. John and Pauline, who often acted as newcomers in other literacy learning activities, were mature group members as they could easily make connections between words they knew in Ojibwe or Oji-Cree and the new Japanese words. Mature group members not only assisted newcomers in class work but also helped by creating a warm, inviting environment. Also related to the importance of relationships, an instructor spoke about Shelly, a former student, who had been reticent to come in the door of the Centre. When she finally felt ready to ask for help with her basic reading skills, her participation in the Learning Centre cultural activities also increased. Over several months, she not only improved her skills in reading and writing but also became more 
outgoing, started an entry-level job at a hotel and found herself in a steady relationship.

Support for this community of literacy learning were described as the floorboards on which the house rests. The Literacy Centre's non-profit community organization, its funding agency and other organizations involved in adult learning in the community supported all of the activities of the Centre. For example, the Centre's board members who had a personal commitment to adult literacy as a foundational skill believed that any results would impact and assist other community members in the region. As a result, cooperative relationships among the eight organizations involved in adult education in the town developed, providing a supportive environment for adult learners at the Literacy Centre. This type of environment was congruent with indigenous culture and respectful of learners' previously negative experiences with formal education. It included a comfortable, relaxed social atmosphere, flexible schedule, and broad but flexible learning expectations. Thus far, as the adult learner portrait emerges, a substantial component is how collaboration among individual adult learners leads to personal growth outcomes that move beyond the short-term acquisition of basic skills. Adding to our composition is a macro-level element that considers the influence of programming, funding and partnership building. Taylor, Widdifield, et al. (2007) examined aspects of collaboration at the broader national program level. More specifically, they investigated partnership development in a case study of the National Literacy Secretariat (NLS) Business and Labour Partnership Program. This program was a large initiative of the Canadian federal government focused on engaging business, labour, educational practitioners, and provincial governments in partnership projects aimed at enhancing adult work-related literacy to improve economic performance and employability. The study examined this funding program from its inception in 1988 through its periods of foundation-building, development and change in 2006. Among the accomplishments achieved by this multitude of partnership projects over 15 years was creation of innovative models for delivering workplace literacy, support for training and consultations, and development of assessment and evaluation tools, such as the Test of Workplace Essential Skills (TOWES).

Drawing from multiple sources of data, including interviews, field notes, archival records and program documents, Taylor, Widdifield, et al. (2007) determined a number of critical factors for collaboration and successful partnership-building in workplace domains. Most relevant to our adult learner portrait, one macro factor identified was "visioning the full range of possibilities with the field...to understand the complexities of workplace literacy...through a social development lens" (p.10). The rudiment of this funding policy reflects how successful outcomes of workplace literacy programs extend beyond literacy and specific work-related technical skills to include social consequences. For the most part, during mandatory cyclical reviews of this funding program, it was found that the lives of adult learners had changed across the various delivery models. These changes included improvement of individual workplace skills but extended into their lives at home and in the community.

Other factors identified for successful partnership building included "respect for stakeholder values, differing points of view and open and frank discussions" among partners and "small projects that focused on local needs" (Taylor, Widdifield, et al. , 2007, p. 10-11). These factors imply the 
importance of being aware of the unique context of a literacy program in order to consider success beyond the individual worker level. Throughout program planning, when stakeholders recognize program goals and processes from other frames of reference, they can come to a better understanding of the extent of learning outcomes required to fully capture program impact. This may be contrasted with the factors which led to unsuccessful partnerships, such as when "project objectives are primarily tied to accountability" and there exists "rigid reporting requirements and micro attention to project financial accountability" (Taylor, Widdifield, et al., 2007, p. 12). Later in the life cycle of the NLS program, a narrower focus on outcomes restricted to standardized measures of essential skills had a negative effect on project impacts.

\section{Adults Acquiring Higher Skills During the Life Course}

As our portrait continues to emerge, we integrate another learning pathway into the composition focusing on learning outcomes observed in the everyday lives of adults with very basic literacy skills. There are three important elements embedded in this path with the first centering on the outcomes for basic level employees in workplace training programs. Highlighted again here is that adult learning outcomes move beyond the traditional short-term measurement of program objectives and illustrates the life-wide changes that employees experience because of workplace training. The second element along this pathway illustrates the informal learning outcomes for IALS Level 1 and 2 adults in their daily literacy practices that are life-deep, while the third describes deaf adult learners overcoming life challenges through the development of novel lifelong learning goals.

\section{Learning Outcomes of Adult Workers with Basic Literacy Skills}

About a decade ago, the Canadian Council on Learning (2008) reported that despite the importance of adult learning, a number of challenges persist. Although rates of participation in adult education and training seemed to increase over the last few years, there are still segments of the workforce with unmet learning needs and those in most need are least likely to get further education and training. One of these groups is adult workers with low literacy skills (Myers \& de Broucher, 2006). Coupled with this problem is the paucity of data about the kinds of formal and informal training activities in which workers with low literacy skills actually participate. An earlier report on the Adult Education and Training Survey (AETS), looking at the training of Canadian workers, defined formal job-related training as courses or programs related to a worker's current or future job (Peters, 2004). These courses/programs have a structured plan whereby an employee, led by an instructor or trainer, follows a program and receives some form of formal recognition upon completion, such as a certificate or a high school diploma. On the other hand, informal job-related training involves little or no reliance on pre-determined guidelines for its organization, delivery or assessment. It does not lead to any formal qualification or certification and is undertaken by the participant with no specific intention of developing job-related skills or knowledge.

In order to understand informal job-related learning and workers with low skills, Taylor and Evans (2009) employed a multi-site case study with 31 employees and 18 instructors from seven different types of workplace literacy programs in Canada and 42 employees and 6 supervisors/ tutors from four workplace basic skills programs 
in England. Findings suggest important learning outcomes that could not be captured by measurement of formal training program objectives alone.

Beyond the immediate intended targets of formal training, a continuous learning outcome was that employee participation in a formal program acted as a catalyst for various informal learning activities that occurred back on the shop floor. Participating in an organized class or tutorial session heightened employee awareness of the importance to learn and take charge of their learning, even beyond the workplace. This interplay between formal and informal training was synergistic. Back on the shop floor, employees experienced a certain assuredness in their literacy skills to self-direct their own learning and try their regular or associated job tasks in different ways by themselves or with others. It seemed that workers began to realize the range of informal learning possibilities available to them. For some employees, the driving force for participation in the formal program was the credential while for others it was the chance of career advancement. However, this external motivation shifted once they became engaged in the more informal learning back on the floor.

Five different types of self-initiated, informal learning activities were identified. The first type, "Observing from Knowledgeables," included learning a new job task or the same task in a different way from a more proficient co-worker or supervisor. This often meant that the worker self-identified a mistake in a job task and searched for an expert to observe doing the same task. "Practicing without Supervision" was a second type of informal learning activity in which workers sought new challenges in their crews where they could practice a skill, like problem solving, or participating in the company in a new way, such as joining a union or health safety committee. A third type was "Searching Independently for Information." Workers often used their reading and computer skills to search for new information on a problem presented in the routines of the workday. Frequently, the Internet, Intranet and work manuals were used for this information search. If employees had already taken a workplace course on computers, there was transfer of learning of those skills back to the unit and if not, some initial guidance by a co-worker on how to perform the computer task was provided. "Focused Workplace Discussions" with peers and supervisors was another type of informal learning. Employees used questioning and summarizing skills to engage in workplace updates. They sometimes exchanged shop talk around work task procedures and updates on new machinery. "Mentoring and Coaching" was the fifth type. Most workers who taught a fellow employee how to perform a job-related task reported that there were many gains by learning in this way. They realized that they first had to talk through the steps of the job task and understand the sequencing before coaching another worker. A common pattern for these types of employees was that they became aware of an increased ability to mentally organize information when demonstrating a task to another worker.

\section{Everyday Literacy Practices of Adults Acquiring Higher Skills}

Whereas the section above shows that informal learning can be a valuable outcome of more formal workplace training, this section illuminates some of the myriad ways in which informal, life-wide learning is experienced by workers and non-workers alike. Using an ethnographic research design, Taylor (2006) broadened the lens of adult literacy outcomes by revealing the interaction of life roles, informal situated learning 
environments, and everyday literacy practices of 10 adults with the most basic levels of competence (IALS Level 1 or 2). Informal learning was operationally defined as any activity involving the pursuit of understanding, knowledge or skills which occurs without the presence of an externally imposed curriculum of formal and nonformal institutional programs.

Life roles which precipitated informal literacy learning consisted of combinations of being a parent seeking better educational opportunities for one's children, being a supportive spouse, partner or family member, giving back to one's community as a volunteer, and striving to be a valued employee. Thus, informal literacy learning took place in three main environments: home, community, and workplace. Some examples of the informal learning that occurred at home included self-directed learning about affordable housing and daycare, budgeting and comparative shopping, home repairs, and school-related homework topics. In the community, individuals learned informally, for example, to take inventory as a volunteer at a school cafeteria or about the muscular system and understanding test results through interactions with a physiotherapist.

At work, employees learned about accident procedures on a safety committee and how to input data into a new shop floor computer. These examples show how literacy practice, including oral communication, reading, writing, numeracy, teamwork, and problem solving, occurs daily, and if the full impact of adult literacy learning is to be recognized, then outcomes that span home, work, and community contexts should be considered.

\section{Deaf Adult Learners Overcoming Life Challenges Through Literacy Practices}

In this third element that follows, results from a case study of the Deaf Literacy Initiative from the Ontario Literacy Basic Skills (Deaf LBS) program are highlighted. The findings suggest that program context, content, individual learner characteristics and instructional style contributed to a reformulated identity for the deaf learners. Participants described how newly acquired literacy practices not only increased their self-esteem but awakened lifelong learning goals. Learners felt more empowered and confident in themselves as both literacy learners and adults. This was, in part, due to the deep reflection that occurred throughout their journeys as deaf literacy learners in a community of practice. According to Taylor and Roberts (2013), both the functional program approach and the individual outcomes enabled learners to create new literacy practices that became ingrained in their everyday lives as social practices.

In this particular program, real world content was layered and organized into modules using learners with mixed abilities in a small group format. For example, learners not only discussed issues revolving around public transportation, but practiced reading bus signs, paying correct fares, filing complaints and following through on complaints. In a nutrition unit, learners focused on how to read food labels to distinguish what could be considered good and bad nutrition. These topics were supported with actual trips to the grocery store using weekly food flyers and newspaper articles (Roberts, 2010). A Quilting module enabled learners to use numeracy and literacy in new ways that were connected to real life experiences. One participant learned how to operate a sewing machine while another identified English words and symbols for different types of cloth. A WHMIS module showed learners new workplace literacy practices such as reading yellow safety boards, hazard symbols, and labels on cleaning products. Learners in a Computers with Seniors module were introduced to software 
to create letters, budget sheets and organized lists for personal and professional reasons. With a personal support workers (PSW) agency located in the same building that housed the Deaf LBS program, workers provided testimonials, experiences from their job sites and access to a long term care facility to learners who were taking a Pre-PSW module (Roberts, 2010). Through these types of interactions, literacy became practices instead of skills. Reading and writing tasks were no longer seen as discrete skills. They became embedded into social practices that allowed learners to become literate in non-traditional ways. As can be seen in the paths of these adults with basic skills, literacy learning can lead to outcomes that are observable in everyday life at home, work, and communities, and can even lead to identity transformation, which is examined in greater detail in the last pathway considered next.

\section{Mature Adult Learners Experiencing Identity Transformation}

For the final component in our portrait, we see how literacy learning and the variety of associated outcomes can have a profound impact on the adult learner. Here, we examine how adults engaged in upgrading, essential skills and workplace training, through formal and non-formal programs, gain awareness of the value of existing social resources, develop new relationships and social skills, and learn to leverage them in support of lifelong, life-wide, and life-deep learning. Such outcomes extend well beyond the instrumental goals typically associated with adult literacy programs and account for some identity transformations that can occur in the lives of adult learners.

Typically, adult literacy and basic skills training has been viewed as preparation for employment, with increased wages and productivity as measurable outcomes. But, as we have come to view literacy as a component of human relationships rather than an individual skill, we must accept the challenge of how to measure the non-economic returns of investment in workplace education, essential skills programs, and workbased learning. This is what Taylor et al. (2012) did when they developed the Social Capital Inventory (SCI). Recognizing that adult learning can often support development of social skills, relationships, trust, engagement, and other unintended consequences that might only be captured by moving from measures of earning toward measures of learning in the broadest sense, and drawing on Lin's (2001) definition of social capital as "the resources embedded in a social network that can be accessed or mobilized through ties in the network" (p. 49), a measure was developed, comprised of four dimensions. These included the quality of one's social networks, such as trust, efficacy, diversity, and inclusivity; the structure of one's networks, which involves size, power relations and modes of communication; the transactions that occur within one's networks, such as sharing support and knowledge; and the types of networks, which include bonding, bridging and linking types.

Applying the SCI, Taylor et al. (2013) investigated the associations among social capital and selfdirected learning readiness using a mixed methods study of adult learners with varied goals. Participants included adults returning to an adult high school to obtain their grade 12 certification with goals of further education and long-term careers, those enrolled in an adult high school custodial training program with goals of immediate job entry, and others engaged in workplace training opportunities with goals of self-improvement. Analysis of quantitative data revealed that these adult learners possessed relatively high levels of self-directed 
learning readiness, as indicated on the SDLRS scale (Guglielmino \& Associates, 2012), and social capital, as indicated by the SCI. Further, interviews with participants suggested how they developed social skills and resources as well as better awareness of the social resources that they already possessed, as they were simultaneously acquiring essential skills in formal and nonformal programs. Some examples of the social capital that developed included greater recognition of the social resources available to them, such as networking with students outside of class, participation in brown bag lunch meetings at work, and travel to workshops. Another occurrence of social capital was the improved confidence to access such resources, including the use of the internet to locate information, use of company policy manuals, and use of software. Also, learners came to believe that they had knowledge and skills worth sharing, as seen in the active contributions they made at work meetings and social committees. Thus, this study showed that adult learners have a readiness to gain much more than just the basic skills that are the overt objectives of many essential skills programs; they also develop relationships and resources that enable continued informal learning at home and the workplace. Coupled with the findings of Taylor and Trumpower (2014) these conclusions demonstrate the value of social and personal outcomes as a means for measuring the success of basic literacy education.

Whether social capital is built in the process of adult learning programs, or adult learners develop a greater awareness of their social resources and subsequent ability to apply their social capital, it is clear that outcomes beyond skill acquisition are important. Indeed, as adult learners gain confidence, knowledge, and skills, they undergo identity transformations that can lead to sometimes profound lifelong learning experiences both within and outside of the workplace. Taylor et al. (2015) conducted a secondary analysis of qualitative data obtained in the Workers and Lifelong Learning project (described by Taylor et al., 2013) and the Developing a National Framework for Essential Skills project (described by Taylor \& Tashereau, 2014). They found that “...environments and approaches leveraged the opportunity presented in essential skills and employment training to also encourage reflection, interaction and outcomes which extended beyond instrumental goals of the programs" (p. 830). Noteworthy is that the instructors of these programs realized the multiple and varied learning goals of trainees that surpass workplace specific skills. As a result, individual assets of the worker and trainee such as enrichment through learning, job satisfaction, increased confidence, feelings of wellness, and self-esteem influenced how they viewed themselves differently. Pivotal to these changes in identity was how the instructors developed self-directed and social learning activities that transferred outside the classroom. Participants learned with and from each other during online activities, small group discussions among individuals with diverse perspectives, and knowledge sharing across workplace departments. And, participants noted instances in which instructors provided support, set a positive tone in the classroom, and established motivating conditions, which led to feelings of safety and trust in the growth process. All of these were transformative factors which permeated their life roles as workers, parents, spouses and community citizens.

In this second example, we describe how adults living with limited literacy and chronic illness made meaning of their patient education experiences and took more control of their lives as a result of the participation in a literacy classroom. 
Using a hermeneutic phenomenological research design, King and Taylor (2010) studied 14 adults enrolled in two basic education programs in Ontario who had chronic illnesses such as asthma, diabetes, high blood pressure, arthritis, or any other physical problem that had lasted for at least nine months. In an attempt to understand patient education experiences of these adults with limited literacy and chronic illnesses, an interplay among various factors was found. For example, participants thought of family members as interpreters, readers, and mediators when they faced barriers to communication with members of the health care team. They asked their children to explain unfamiliar terms that a doctor had used and took home patient education pamphlets so their children could help them with the reading.

As well, these adult learners felt that health care providers did not listen to them or explain their medical problems and treatments in a way they could understand. This resulted in feelings of mismatched expectations with the health care providers which led them to believe that they lived between two worlds. They perceived themselves as different from others in society who were well and lived healthy lives. These learners also believed that because they had gone back to school to improve their literacy abilities, they were different from the majority of society whom they perceived as having no difficulties with literacy. As a result, they harbored feelings of powerlessness, including a fear of exposure rooted in the experience of living with limited literacy.

Perhaps the most significant finding was the individual transformation that each participant experienced following daily participation in the basic education program. Learning activities developed into a community of practice, allowing participants to overcome, or at least lessen, some barriers they faced, take greater control of their lives, and manage their chronic illnesses better. For example, participants encountered difficulty obtaining or understanding patient education information intended to help them manage their chronic illnesses. However, as their reading skills and self-efficacy improved through the communities of practice that developed in the literacy classroom, they were better able to find and interpret health information on their own.

\section{A Portrait of the Adult Learner with Cross-National Perspectives}

In the following discussion, we draw from the range of literacy outcomes discussed above through various settings and learning pathways to sketch a portrait of the adult learner. Although drawn from Canadian "ink," we illustrate how the portrait is reflective of adult learners across other countries, as well.

A first feature in the portrait is collaboration among individual adult learners leading to personal growth outcomes. Being part of a community of learning serves as practice for trying out newly developed literacy and social skills within a safe environment, including the capability for selfdirected learning. In the United Kingdom, for instance, a collaborative peer-led reading program for literacy learners in prison enabled participants to re-imagine themselves as social actors and connect their learning to self-directed identity building (Kendall \& Hopkins, 2019). And in the United States, collaboration in a community of church-based ESL programs empowered Latino and Asian learners to discover and acquire funds of knowledge and find their voices in the larger society (Chao \& Mantero, 2014).

This first feature of adult learners is supported by instructors who are aware of their own teaching beliefs and use enabling rather than directive teaching styles. For instance, in Western Australia 
and New Zealand, McHardy and Chapman (2016) argued that instructors of less skilled adult readers must first understand their own beliefs about teaching, and their consequences, before they can effectively respond to learner needs. The various learning outcomes associated with this feature of the adult student appears related to the development of meta-cognitive abilities. As Talwar et al. (2018) maintain, to improve literacy programs, instructors need a better understanding of the cognitive profiles of adults who struggle with reading.

A second feature of our adult learner portrait focuses on informal learning outcomes and the importance of supports during informal training. International reflections of this feature can be seen in pineapple farmers in Thailand who used nonformal vocational training to develop higher skills and improve the rural economy (Suebnusorn, 2016). In this training program, trust was developed between farmers and pineapple processing factories as the farmers learned new planting skills and needs of the factories. Referred to as "informal workers," back on their farms they informally learned to keep records, calculate costs, and plan their cultivation. In the United States, Copeland et al. (2016) showed how adults with extensive support needs can enhance their opportunities for a meaningful life, acquiring literacy skills across the lifespan if supports are in place, such as being taught using a multi-component approach. Similarly, the deaf learners reported earlier overcame life challenges through literacy practices as their teachers used a multi-layered approach, focusing on real world content both in the classroom and in the daily environments of the learners. As Keiko and Black (2016) claim, despite the economic discourse that has dominated discussions about literacy and numeracy, adults find places and spaces to continue their desire for learning during the life course based on the lived experiences they have in their communities.

A third feature in the portrait depicts adult learners building relationships, experiencing identity transformation, and developing social capital. In an Australian context, Black et al. (2006) asserted that formal adult literacy and numeracy courses have a complex mix of results that combine social and human capital outcomes and that these effects have a socio-economic impact. In a similar vein, but using U.S. data from PIACC, Calonie and Gray (2018) suggest that profiles of human and social capital can help understand education needs of adult immigrants. By understanding the unique skillsets among immigrant learners, customized approaches capitalizing on these assets can increase the capacity for service providers to serve. Also related to pre-literate ESL learners in an Australian context, Atkinson (2014) argues that programs need to be reframed with a social and holistic orientation to acknowledge learners' emerging sense of identity. Casey and Asamoah (2016) summarize by stating that humanistic non-formal and informal learning practices foster transformation, development and human relationships.

On an endnote, we ponder the funding policies and types of adult literacy learning that are presented here. One way forward is to continue to advocate for national adult basic education systems that acknowledge all types of learning gains. As Belzer and Kim (2018) claim "not only would such a system benefit learners, but it would also have a social return in improved health outcomes and civic engagement and most probably on other important social measures" (p. 607). Finally, there is much hope that resonates from the actual adult literacy classroom where practitioners can act as action researchers to identify the new kinds of learning outcomes that are being voiced by a different and diverse adult student. 


\section{References}

Atkinson, M. (2014). Reframing literacy in adult ESL programs: Making the case for the inclusion of identity. Literacy and Numeracy Studies, 22(1), 3-20.

Aspin, D., Evans, K., Chapman, J., \& Bagnall, R. (2012). Introduction and overview. In D. Aspin, J. Chapman, K. Evans, \& R. Bagnall (Eds.). Second international handbook of lifelong learning, part 1 (pp. xlv-lxxxiv). Springer.

Belzer, A., \& Kim, J. (2018). We are what we do: Adult basic education should be about more than employability.Journal of Adolescent \& Adult Literacy, 61(6), 603-608.

Black, S., Balatti, J., \& Falk, I. (2006). Social capital outcomes: The new focus for adult literacy and numeracy course. Australian Journal of Adult Learning, 46(1), 318-325.

Calonie, M. \& Gray, I. (2018). Using profiles of human capital and social capital to understand adult immigrants' education needs. Adult Education Quarterly, 69(1), 3-23.

Canadian Council on Learning. (2008). Reading the future: Planning to meet Canada's future literacy needs.

Casey, C., \& Asamoah, L. (2016). Education and sustainability: Reinvigorating adult education's role in transformation, justice and development. International Journal of Lifelong Education, 35(6), 590-606.

Chao, X. \& Mantero, M. (2014). Church-based ESL adult programs: Social mediators for empowering family literacy ecology of communities. Journal of Literacy Research, 46(1), 90-114.

Copeland, S. R., McCord, J. A., \& Kruger, A. (2016). A review of literacy interventions for adults with extensive needs for supports. Journal of Adolescent \& Adult Literacy, 60(2), 173-184.

Guglielmino \& Associates (2012). What is the self-directed learning readiness scale? http://www.lpasdlrs.com/

McHardy, J., \& Chapman, E. (2016). Adult reading teachers' beliefs about how less-skilled adult readers can be taught to read. Literacy and Numeracy Studies, 24(2), 24-42.
Hauer, D. \& Taylor, M. (2008). Collaborative learning in an Aboriginal adult literacy centre. Proceedings of the $27^{\text {th }}$ Annual Conference of the Canadian Association for the Study of Adult Education (pp. 171-175).

Hill, L. (2017). Adult education in an age of assessment and accountability. In S. Conceicao, L. Martin \& A. Knox (Eds.). Mapping the field of adult and continuing education: An international compendium. (pp. 265268). Stylus Publishing.

Keiko, Y. \& Black, S. (2016). Beyond economic interests: Critical perspectives on adult literacy and numeracy in a globalized world. Sense Publishers.

Kendall, A. \& Hopkins, T. (2019). Inside out literacies: Literacy learning with a peer-led prison reading scheme. International Journal of Bias, Identity and Diversities in Education, 4(1), 82-99.

King, J. \& Taylor, M. (2010). Patient education for adults with limited literacy and chronic illnesses. Adult Basic Education and Literacy Journal, 4(1), 24-33.

Knox, A., Conceicao, S., \& Martin, L. (Eds.). (2017). Mapping the field of adult and continuing education: An international compendium. Stylus Publishing.

Lin, N. (2001). Social capital: A theory of structure and action. Cambridge University Press.

Myers, K. \& de Broucker, P. (2006). Too many left behind: Canada's adult and education training system. Canadian Policy Research Networks Inc.

Osmond, P. (2016). What happened to our community of practice? The early development of adult basic education in NSW through the lens of professional practice theory. Literacy and Numeracy Studies, 24(2), 3.

Peters, V. (2004). Working and training: First results of the 2003 Adult Education and Training Survey. Human Resource and Skills Development Canada and Statistics Canada.

Roberts, M. (2010). A case study of adult deaf learners: Literacy practices through a socio-cultural lens. [Unpublished master's thesis]. University of Ottawa. 
Suebnusorn, W. (2016). Non-formal vocational education for pineapple farmers: Promoting relevance of education to rural economy. Journal of Education and Research, 6(1), 27-42.

Smith, M. (2017). Differences in reading practices and literacy proficiencies among adults. Reading Research Quarterly, 31(2), 196-219.

Talwar, A., Greenberg, D., \& Li, H. (2018). Does memory contribute to reading comprehension in adult who struggle with reading? Journal of Research in Reading, 41(S1), S163-S182.

Taylor, M. (2006). Informal adult learning and everyday literacy practices. The Journal of Adolescent and Adult Literacy, 49(6), 500-509.

Taylor, M., Abasi, A., Pinsent-Johnson, C., \& Evans, K. (2007). Collaborative learning as the catalyst in communities of literacy practice. Adult Basic Education and Literacy Journal, 1(1), 4-11.

Taylor, M., \& Evans, K. (2009). Formal and informal training for workers with low literacy: Building an international dialogue between Canada and the United Kingdom. Journal of Adult and Continuing Education, 15(1), 37-54.

Taylor, M., Evans K., \& Abasi, A. (2007). Understanding teaching and learning in adult literacy training: Practices in Canada and the United Kingdom. Literacy and Numeracy Studies: International Journal in the Education and Training of Adults, 15(2), 57-72.

Taylor, M., King, J., Pinsent-Johnson, C., \& Lothian, T. (2003). Collaborative practices in adult literacy programs. Adult Basic Education: An Interdisciplinary Journal for Adult Literacy Educators, 13(2), 81-99.

Taylor, M., \& Roberts, M. (2013). Adult literacy and learning disabilities. In T. Nesbit, S. Brigham, T. Gibb, $\&$ N. Taber (Eds.). Building on critical conditions: Adult education and learning in Canada. (pp. 232-242). Thompson Educational Press.

Taylor, M., \& Tashereau, S. (2014). Moving forward on a national strategy for developing essential skills. Canadian Journal of Action Research, 15(1), 54-68.
Taylor, M. \& Trumpower, D. (2014). Adult high school learners: Engaging conditions in the teaching and learning process. International Forum of Teaching and Studies, 10(2), 3-12.

Taylor, M., Trumpower, D., \& Pavic, I. (2012). A social capital inventory for adult literacy learners. International Forum for Teaching and Studies, 8(2), 12-24.

Taylor, M., Trumpower, D. \& Pavic, I. (2013). Unravelling the lifelong learning process for Canadian workers and adult learners acquiring higher skills. Journal of Research and Practice for Adult Literacy, Secondary and Basic Education, 3(2), 95-107.

Taylor, M., Trumpower, D., \& Purse, E. (2015). The role of work-related learning in the identity transformation of Canadian workers with low literacy skills. International Review of Education, 61(1), 815-833.

Taylor, M., Trumpower, D., \& Purse, E. (2017). Adults with low literacy skills. In S. Conceicao, L. Martin \& A. Knox (Eds.). Mapping the field of adult and continuing education. (pp. 87-92). Stylus Publishing.

Taylor, M., Widdifield, C., \& Goh, S. (2007). Fostering partnership development in workplace literacy: A case study of the Canadian National Literacy Secretariat Business and Labour Partnership Program. New York Journal of Adult Learning, 5(2), 5-18.

Tett, L. (2018). Participation in adult literacy programs and social injustices. In M. Milana, S. Webb, J. Holford, R. Walker \& P. Jarvis (Eds.). The Palgrave international handbook on adult and lifelong education and learning (pp. 359-374). Palgrave-Macmillan.

UNESCO Institute for Lifelong Learning. (2009). Global report on adult learning. Oxford University Press/ UNESCO Publishing.

Werquin, P. (2010). Recognizing non-formal and informal learning. OECD Publishing. 